\title{
Políticas públicas y renovación urbana en Guayaquil: las administraciones social cristianas (1992-2000)
}

\author{
Public policy and urban renovation in Guayaquil: \\ the christian social administrations (1992- 2000)
}

\author{
Gaitán Villavicencio *
}

\begin{abstract}
Resumen
Siendo todo proceso de urbanización un enclave de conflictos de intereses y luchas sociales, resulta interesante comprender en qué medida el proceso de planificación y de gestión urbana de una ciudad como Guayaquil refleja un particular modelo ideológico-político: el que estuvo a cargo del Partido Social Cristiano durante más dos décadas y que llevó a cabo un particular modelo de gestión empresarial de gestión urbana. Es muy ilustrativa la transición de una gestión urbana de las décadas anteriores dominada por estrategias clientelares, con resultados más o menos caóticos y un modelo inversionista de administración municipal.
\end{abstract}

\section{Palabras claves}

Gobierno local, urbanización, gestión municipal, políticas sociales, desarrollo urbano, partidos políticos.

\begin{abstract}
As many processes of urban development are focal points for conflicts of interest and social struggles, it appears very interesting to understand to what extent urban planning and management processes convey a particular ideo-political model in a city like Guayaquil: such as the model undertaken by the Christian Social Party over the past two decades, in which an approach to business management of urban administration was applied. The transition from urban administration from past decades "plagued by client-based strategies with somewhat chaotic results" to an investment model of council administration can be very illustrative.
\end{abstract}

\section{Key words}

Local government, urban development, council management, social policy, political parties.

Forma sugerida de citar: VILLAVICENCIO, Gaitán (2012). "Políticas públicas y renovación urbana en Guayaquil: las administraciones social cristiasnas (1992-2000)", en: Universitas, X (17), julio-diciembre, pp.69-88. Quito: Editorial Abya-Yala.

\footnotetext{
* $\quad$ Profesor de la Universidad de Guayaquil. Director del Centro de Estudios Regionales.
} 


\section{Introducción}

La ciudad es una estructura compleja, dinámica, cambiante, que alberga en su interior una cantidad de componentes contradictorios pero activos que se traducen en procesos encontrados o conflictivos, que determinan su desarrollo o estancamiento. Pero el desarrollo del capitalismo en su fase actual ha traído consigo una nueva configuración espacial del mundo, principalmente, en los aspectos: económicos, políticos, sociales y culturales, en los niveles global, nacional, regional y local, como lo señala Ricardo Lagos y Carlos Fuentes (2012),, "reflexionando, inclusive, sobre una sociedad cuya globalización tecnológica y económica no parece haber alcanzado a la política".

Lo que hace que las naciones, o sus territorios, se relacionen más, directa o indirectamente, para aprovecharse -según posiciones hegemónicas y/o económicas- de sus materias primas, de la extracción de recursos naturales o de la mano de obra barata. También ubicando inversiones directas que provocan fragmentación en todos los niveles antes mencionados. Una de las características de este nuevo capitalismo es la unificación del mercado mundial a través de la modernización tecnológica en la era de la información, imponiendo su dinámica territorial de desarrollo desigual y de inclusión/exclusión que transforma la vida de los pueblos a través de las telecomunicaciones e informática a nivel mundial en tiempo real.

Y que ha sido estudiada por Manuel Castells en su trilogía La era de la información: economía, sociedad y cultura (1997)²; y nos sugiere su lectura que Ecuador, en general, y Guayaquil, en particular, no son la excepción.

Señala también que, "De esta nueva sociedad no podemos hacer aún un dibujo preciso ni establecer predicciones concretas sobre su evolución, pero sí que es una sociedad de redes". Y que, "El ámbito geográfico que adquiere cada vez más relevancia son las regiones metropolitanas, formadas por constelaciones urbanas integradas funcionalmente y socialmente interesantes, unidades metropolitanas cada vez más entrelazadas por infraestructuras físicas y virtuales. Los sistemas de comunicación avanzados crean una nueva geografía,

1 FUENTES, Carlos y Ricardo Lagos (2012). El siglo que despierta. México: Editorial Taurus.

2 CASTELLS, Manuel (1997). La era de la información: economía, sociedad y cultura. Madrid: Alianza Editorial. 
caracterizada por la concentración y a la vez por la descentralización, que en este caso no son conceptos opuestos sino que describen nuestra realidad". 3

Estamos generando una arquitectura espacial de concentración/descentralización, tanto en el entorno urbano como en los flujos de población y actividades. Ya no podemos hablar de centro y periferia sino de diferentes centros conectados entre si, como lo veremos en el caso de Guayaquil en el momento actual.

\section{Antecedentes sobre la aglomeración y su situación actual}

A lo largo del siglo XX, Guayaquil se (re)confirmó como un centro primado en la red urbana nacional conjuntamente con Quito, debido a la importancia que adquiere como el primer puerto marítimo internacional dentro del modelo agroexportador que nos vincula al mercado mundial (cacao, balsa y caucho, banano, arroz, etc.). Situación que le permitió diversificar sus funciones urbanas como ciudad comercial de acogida-bodegaje y de tránsito de la producción primaria exportable del litoral.

El papel en la división espacial del trabajo nacional y su creciente importancia en el proceso de urbanización la convirtió en un objetivo muy apreciado en la lucha y conflictos políticos del país. Su importancia económica determinó su protagonismo político como lo demuestran el 15 de noviembre de 1922, el 28 de mayo de 1944, 2 y 3 de junio de 1959, las luchas contra la dictadura militar de 1963, entre otros hechos históricos destacables. Fue el bastión electoral del "eterno" presidente Velasco Ibarra, de la insurgencia y fortalecimiento de Concentración de Fuerzas Populares (CFP) de Guevara y "Don Buca", de la costeñización del Partido Social Cristiano (PSC), o del ascenso vertiginoso del Partido Roldosista Ecuatoriano (PRE).

Así mismo, la aglomeración se convierte en la sede de los grupos económicos más importantes del país e históricamente poderosos. Es la cuna del proceso de industrialización con la implantación de los ingenios azucareros de Valdez y San Carlos; y, después acoge a las industrias para la sustitución de importaciones, pero no para exportar sino para abastecer al incipiente mercado

3 CASTELLS Manuel (2006): Discurso de ingreso a la Real Academia de Ciencias Económicas y Financieras; Barcelona; 16 de febrero; 9 págs. 
interno, y que son barridas por la crisis de la deuda externa de 1982 y la aplicación intermitente del ajuste estructural (Rojas y Villavicencio, 1988). ${ }^{4}$

Esta situación provoca, hasta la fecha, las fortalezas y también las debilidades, inclusive determina las amenazas y la superación de éstas. Los problemas de Guayaquil y sus vulnerabilidades son históricos, la pésima gestión local del PRE fue el detonante de situaciones acumuladas y no enfrentadas por las élites y los gobiernos, o por sus ciudadanos en las calles.

En resumen, desde el 10 de agosto de 1979, retorno al régimen constitucional, a 1992, a nivel municipal, en Guayaquil los tres elementos descollantes fueron: la gran inestabilidad institucional y administrativa, la duración promedio de un alcalde era de menos de dos años; y, la incapacidad e ineficiencia que estos mostraron durante su corta gestión.

\section{Situación actual ${ }^{5}$}

En las últimas dos décadas (1992-2012) se pueden observar un conjunto de tendencias y hechos en el proceso de urbanización guayaquileño, que como a nivel nacional y regional, afectan directa y diferenciadamente a los actores sociales y políticos como a los agentes económicos de la red urbana como de los centros poblados vecinos, particularmente la aglomeración en estudio, tanto en lo relacionado con la producción del cuadro construido, la estructura de la propiedad del suelo urbano, el desarrollo de formas de la promoción inmobiliaria, como en los alcances de las demandas urbanas agregadas y en las políticas urbanas en aplicación; todo dentro del actual contexto de globalización y desregulación/estatalidad en que están insertos la región, el país y un centro primado como Guayaquil y su entorno territorial.

Cabe señalar que según el V censo de población de 1990, Guayaquil contaba con 1.508.444 habitantes y una planta urbana de alrededor de 18.385 has.; mientras que de acuerdo al último del 2010 cuenta con 2.278.671 residentes en una superficie de 34.449 has, lo que ha hecho que la densidad poblacional baje

\footnotetext{
4 Rojas, Milton y Gaitán Villavicencio (1988). Proceso urbano de Guayaquil. 1870 -1980. Guayaquil: ILDIS-CER-G.

5 Villavicencio, Gaitán (2010) : “Guayaquil: Del Río Grande y el Estero”; Expreso, Guayaquil, 9 págs.
} 
de 82 a 66 habitantes y la tasa de crecimiento descienda de $2,91 \%$ a $1,54 \%$ en estas dos décadas.

Con la fuerza tomada por la propuesta de modernización del Estado, en la segunda mitad de la década de los 80 , impulsada bajo la condicionalidad de los organismos multilaterales de financiamiento, esta se tradujo para los ejecutores nacionales principalmente en el achicamiento del Estado y la privatización de los activos del mismo, lo que nos indica una lectura sesgada y especial de la modernidad como del tipo de Estado a desarrollarse.

En este contexto, las ciudades y sus gobiernos también fueron embarcadas en la "modernización" urbana como parte de las transformaciones al Estado. Así como también, a partir del caos e inestabilidad administrativa que se produjo en Guayaquil durante las administraciones municipales de la década del 80, en particular las marcadamente clientelares, como fueron las del PRE y sus aliados locales, que obligaron a la intervención del gobierno central por la crisis de los servicios públicos, en particular la recolección de desechos sólidos. En ese mismo momento se daba un caso diferente, ese sí digno de imitarse, como era el del Municipio de Quito que estaba asumiendo o recuperando con gran diligencia institucional y técnica las competencias que debería tener un Distrito Metropolitano (1992), que había asumido un tipo de gestión consensuada y de gran convocatoria social como se dio con Rodrigo Paz.

Estas situaciones se van a revertir durante la década del 90, en Guayaquil "positivamente" con el ascenso de Febres Cordero a la alcaldía y "negativamente" por los fracasos sucesivos de las administraciones quiteñas del Maestro Juanito (Herdoíza), Jamil Mahuad y Roque Sevilla.

Se debe destacar el protagonismo paulatino que han ido asumiendo algunos gobiernos seccionales: consejos provinciales y municipios, en comparación a la incapacidad y desprestigio del Estado central, hasta el 2007, consecuencia de múltiples factores históricos y coyunturales. Se destacan el Municipio de Quito bajo la gestión de Rodrigo Paz, los municipios pequeños bajo la administración de líderes indígenas como Cotacachi, Guamote, Pujilí, y en cantones como Guaranda, Loja, Ambato, con dirigentes mestizos; también Consejos Provinciales como los de Esmeraldas, Pichincha, El Oro, entre los más protagónicos.

Como consecuencia del protagonismo relativo alcanzado por los municipios, gracias al aumento de la inversión estatal descentralizada que ha crecido 
en los últimos 10 años del $20 \%$ al $50 \%$ más el aumento de las rentas propias ${ }^{6}$, han desarrollado una gama de operaciones urbanísticas, donde se destaca especialmente el caso de Guayaquil, las cuales han respondido a políticas urbanas específicas marcadas por el elitismo, el mercado y un proyecto histórico inacabado de ciudad vehiculado por el ejercicio de un poder vertical, que solo en el caso de la urbe porteña se da continuadamente por dos décadas. "Ya que solo construyen la ciudad quienes tienen poder para hacerlo", como lo señala Esteban Ruiz Ballesteros (2000: 10). ${ }^{7}$

En fin, con la elección de Febres Cordero, en 1992, se inició una etapa de estabilidad administrativa y de continuidad de las políticas y programas de desarrollo urbano, que actualmente es seguida por Jaime Nebot, ambos pertenecientes al PSC, que interpelamos y evaluamos sus resultados y el modelo implícito en que se sustenta.

\section{Guayaquil: de 1992 al 2000 , el inicio de la regeneración}

La crisis urbana generalizada de Guayaquil tocó fondo en 1992. La gestión dinástica del PRE coadyuva a profundizarla; $y$, contradictoriamente a desacreditar a las administraciones basadas exclusivamente en el manejo populista del gobierno local y el poder para usufructo de un reducido grupúsculo de incondicionales, hasta la perdida del sentido común y la ética; y, cuando la aglomeración se encontraba sumergida en una precaria situación que por sus dimensiones y efectos había provocado malestar en la convivencia citadina y el colapso de casi todos los servicios públicos; la misma ya había tocado fondo en realidad, y más no se podía degradar a una ciudad según el discurso político dominante. $^{8}$

Lo que permitió, en agosto de 1992, por elecciones democráticas, el acceso al sillón de Olmedo de la derecha populista encabezada por León Febres Cordero, indiscutible líder carismático del PSC, con la colaboración de grupos

6 Rentas/AME/Descentralización. Según el AME y varios autores consultados como Fernando Carrión y Luis Verdesoto, que el presupuesto de los municipios ha crecido en los últimos 15 años del $20 \%$ al $50 \%$ más el aumento de las rentas propias.

7 Ruiz Ballesteros, Esteban (2000): “Construcción Simbólica de la Ciudad”; Miño y Dávila Editores, Madrid, pág. 10 .

8 Ver: Andrade, Javier, (2006): "Mas Ciudad”, menos ciudadanía: renovación urbana y aniquilación del espacio público en Guayaquil; en Ecuador Debate \# 68; Quito; Agosto 2006; Págs. 161-198. 
económicos locales y la simpatía de crecientes grupos vecinales que miraban a este como el "salvador" de Guayaquil.

El nuevo alcalde basó su estrategia de recuperación "integral” de la ciudad en las siguientes líneas de trabajo: el cambio total de la casa (Palacio Municipal), las obras de hierro y cemento que se vean e impacten política y socialmente -inicialmente improvisando como sucedió con los viaductos y pasos a desnivel-, la titularización de la tierra y el financiamiento municipal, a través del incremento significativo de las rentas propias.

Posteriormente se agregan a esos discutibles éxitos de esta primera gestión local socialcristiana el Malecón 2000 y la Regeneración Urbana que van a constituir la "urbanización", ${ }^{9}$ obras comunes y vacías de contenido que van a incidir en la construcción segregada y de referentes simbólicos de la ciudad "recuperada/transformada" a través de la expresión de un poder urbano verticalista y autoritario del líder político sobre la sociedad local y el conjunto de las élites citadinas dominantes.

Además se destacan, dentro de la "estrategia del hierro y cemento", la construcción de la red de mercados y su funcionamiento disciplinado cuasi policial, el ordenamiento compulsivo de las bahías y la expulsión de los informales de las aceras del centro histórico y comercial porque malograban la "regeneración urbana". Conjuntamente, con la concesión de varios servicios públicos como el relleno sanitario de Las Iguanas; la limpieza, recolección y acarreo de desechos sólidos; $\mathrm{y}$, el abastecimiento y distribución del agua potable y la gestión del alcantarillado sanitario y pluvial.

Finalmente, no se puede dejar de reconocer que este alcalde inicia un modelo particular de gestión de la ciudad y de desarrollo urbano de tipo empresarial, que se ha seguido posteriormente en varias ciudades intermedias y secundarias de la costa ecuatoriana, como Manta, Machala, Daule, Samborondón, entre otras, que ha impactado en el imaginario colectivo de sus vecinos pero que no ha generado ciudadanía, ya que "Guayaquil, vive por ti".

9 Ver: Francesc Muñoz (2008). urBanalización. Paisajes comunes, lugares globales; Edit. Gustavo Gili, Barcelona, 216 págs. 


\section{Guayaquil, del 2000 al 2012 , la plenitud de la regeneración, o "más ciudad"}

Apenas el alcalde Febres Cordero anunció que no se lanzaba a una nueva re elección, todo el mundo sabía que el sucesor natural era Jaime Nebot, lo que sucedió también en las urnas. Actualmente, va por la finalización de su tercer período; y, obviamente tenemos que destacar diferencias con su antecesor incluyendo el programa ejecutado en la gestión del cantón.

Entre las diferencias mencionaremos, la continuación de los programas anteriores, arriba mencionados, pero con la inclusión de una estrategia de desarrollo social, asumir la plena responsabilidad -no compartida políticamente con nadie- en las decisiones de la administración local; y, consolidar una propuesta de ciudad futura para las nuevas actividades económicas, como el turismo, emprendimientos, malls y la marca ciudad, aún en construcción y casi en ciernes.

Desde la profundización y pulimiento del modelo de gestión empresarial de la urbe, delineado por la administración anterior, Nebot ha impulsado un programa de macro obras urbanísticas de múltiples impactos, como la recuperación ecológica de los esteros con la implementación de malecones y parques en ambas riberas del estero Salado; la construcción de nuevos puentes, como el del Velero o el que empata con la calle Gómez Rendón; la ampliación y mejoramiento del sistema vial metropolitano con las co-urbaciones; continuación del programa de regeneración urbana inclusive en sectores suburbanos como El Guasmo, Flor del Bastión, o el suroeste; impulsar la dotación del agua potable y alcantarillado; y, la construcción de parques y áreas de esparcimiento en el conjunto urbano, entre otras obras. A partir del perfeccionamiento y acuerdos de funcionamiento con el Gobierno Central de varias Fundaciones, que le han facilitado la definición y ejecución de las obras físicas como la operación y mantenimiento de las mismas de una manera eficiente y corporativa.

Mención aparte amerita la metrovía con sus tres ramales que atraviesan la ciudad por los cuatro puntos cardinales, actualmente dos están en pleno funcionamiento y el otro está por finalizarse su construcción para la puesta en marcha. Mientras en la parte social se destaca el impulso dado al programa Más Salud, con siete hospitales del día, cuatro dispensarios y 36 clínicas móviles, incluyendo entrega de medicamentos; en educación, con la construcción o mejoramiento de los locales escolares, dotación de equipamientos informáticos, de 
Gaitán Villavicencio. Políticas públicas y renovación urbana en Guayaquil:

las administraciones social cristianas (1992-2000)

libros y uniformes y programas de formación y capacitación on line, o en los CAMI, entre otros.

\section{Entre el Guayaquil "vive por ti" y "más ciudad": resulta- dos de un modelo de gestión urbana}

La evaluación del primer gran período institucional y de continuidad administrativa y programática en toda la historia de la ciudad, obviamente que obliga a que se observen sus avances como también sus falencias y estancamientos, desde la perspectiva de una mano de cal y otra de arena, para que no primen la subjetividad y la ideologización; y que en el análisis sobresalga la objetivad, verificación y enfoque científico. Así mismo, 20 años no son una garantía para el futuro próximo que en el momento que haya un cambio administrativo continuarán las políticas o programas establecidos, o la institucionalidad imperante.

Guayaquil, según el Esquema Urbano de 1975 " "ha incrementado su población en un 4,8 veces en 40 años". Sin embargo, el ritmo de crecimiento ha disminuido paulatinamente, desde una tasa de crecimiento poblacional de $5,66 \%$ en 1950 , a una de $2,87 \%$ entre $1982-1990$, actualmente según el Censo del 2010 es de 1,54\%. A lo largo de este proceso, la ciudad ha tenido paralelamente un acelerado y descontrolado crecimiento de su planta urbana, lo que ha incidido en las bajas densidades y dificultades en la dotación de los equipamientos e infraestructuras colectivas, debido al patrón de localización y ocupación del suelo urbano, agudizando el panorama de segregación socioresidencial vigente.

En este hipertrofiado proceso de urbanización se destaca, como rasgo llamativo, el crecimiento de una serie de co-urbaciones que han hecho que el tejido urbano se salte límites y competencias político-administrativos, que nos señala la existencia de una situación de metropolización, no reconocida por el derecho urbano ni las autoridades locales respectivas.

La metropolización de Guayaquil se dispara en varias direcciones, de una manera tentacular, como son los cantones Samborondón, Durán, Nobol y hacia el kilómetro 27 (sectores Yaguachi, Taura y Milagro), Daule y Salitre. Porciones significativas de territorios de estos cantones hacen parte de la trama urbana 
metropolitana guayaquileña, bajo diferentes modalidades inmobiliarias, como urbanizaciones, lotizaciones, áreas de reserva, haciendas, zonas periurbanas, etc.; $y$, constituyen los sectores de crecimiento más dinámicos para la aglomeración y promisorias tierras de "engorde" (valorización) para el mercado del suelo urbano y la vivienda; a lo que se agregan una serie de iniciativas viales, o proyectos estratégicos, destacándose, principalmente, una red vial de primer orden y en buen estado de mantenimiento, financiada por el Estado central a través del MTOP y entregada al Gobierno Autónomo Descentralizado Provincial que la ha concesionado en su totalidad; otras están financiadas por el Gobierno Provincial en alianza con el MTOP y los GAD's municipales. Estos circuitos viales facilitan la movilidad y hacen que se dimensione una gestión y ordenamiento metropolitano en ciernes, pero que crece caóticamente dirigida por fraccionadores y promotores que se benefician privadamente.

En todo este gran territorio, como en su cuadro construido, se han impulsado en estos últimos 20 años una serie de acciones institucionales y de operaciones urbanísticas e inmobiliarias, como también se han producido localizaciones y relocalizaciones de actividades económicas y de consumo colectivo, implantación o cambios de usos del suelo, que han provocado diferenciados procesos de valorización del suelo urbano y múltiples formas de ingresar la tierra al mercado, como también han generado una nueva imagen de la ciudad metropolitana y, con ello, nuevas formas de dominación y hegemonía urbanas. La gestión de los municipios es totalmente descoordinada, diferenciada y desproporcionada, ya que sobresale el facilismo y la menor exigencia de trámites burocráticos.

Entre los principales eventos y acciones que han marcado el desarrollo de las administraciones edilicias socialcristianas y del sector privado en Guayaquil y su área metropolitana se pueden reseñar los siguientes:

Para las áreas de concentración de la pobreza urbana se han impulsado pasos a desnivel, regeneración de calles, cuarteles policiales, el complejo turístico "La Playita" en el Guasmo, centros recreacionales y deportivos (Viernes Santo en la Fragata, Balneario Puerto Hondo, Parque Ecodeportivo en Isla Trinitaria y Parque Sectorial Pascuales), el polifuncional de Bastión Popular del Proyecto Zumar, como el Programa de Barrios de Excelencia. Inclusive, "La Federación de Barrios Suburbanos-FEDEBAS- reclama su parte. Sus dirigentes insisten en que la obra pública se quedó en las zonas comercial, bancaria y turística", aunque el Municipio responde "que también se consideró a lugares marginales, como Mapasingue (Norte), para ejecutar el programa de barrios de excelencia. 
Además, la imagen de la calle Portete (sur) también se cambió, como en el centro"11.

Vale recalcar que para el Alcalde Nebot se deben "crear más centros de generación de autoestima como éstos, en otros sectores de la ciudad". En otra declaración a la prensa en la relación a las obras populares decía: "El progreso no espera, la injusticia tiene que ser vencida, la pobreza tiene que ser atacada y ese es el papel nuevo de las ciudades" 12 .

Desde los años 80 hasta la fecha, se han venido produciendo paulatinamente en la aglomeración una cierta especialización, o marcaje, de los sectores de la urbe, y el aparecimiento de nuevas centralidades-todavía no consolidadas ni legitimadas socialmente- especialmente en el norte, a partir de los grandes ejes viales, en particular de ciertas vías arteriales que han condicionado y conllevado el cambio de usos de suelo ${ }^{13}$. De una manera difusa y en menor escala también se configuran larvadamente en el sur y en suroeste de la ciudad.

También debe incluirse aquí lo que se estuvo impulsando por parte de la promoción inmobiliaria privada, antes crisis de 1999, en la Avda. Francisco de Orellana hasta el cruce con la Avda. Tanca Marengo, llamada también Kennedy Norte, como un distrito de negocios y del terciario superior (C.B.D), que aún está en expansión. El desarrollo de estos ejes viales ha marcado las diferencias urbanas y los niveles de segregación socio-residencial, agudizando en Guayaquil las situaciones de desigualdad y exclusión. En estas áreas se está aplicando de manera extensiva el programa de regeneración urbana, que consiste en el mejoramiento de las vías, aceras y bordillos y dotación de ciertos mobiliarios urbanos y pintada de las fachadas, que deberán pagar anualmente los propietarios inmobiliarios en su factura de impuestos prediales con los intereses del caso por tratarse de un crédito municipal. ${ }^{14}$

11 Suplemento “ Guayaquil Más Ciudad”, \# 27, octubre 2006.

12 La Revista Dominical del Diario El Universo, 20 de julio del 2003.

13 Como es el caso de la Víctor Emilio Estrada en Urdesa, zona rosa de esparcimiento y servicios; La Garzota-Guillermo Pareja, donde se han asentado comercios y servicios formales; el caso del barrio Orellana, que está cambiando de residencial a servicios, en particular oficinas. Kennedy Norte, como un distrito de negocios y del terciario superior (C.B.D), que está en expansión aún con los problemas derivados de las crisis económico-financieras del 1999-2000. Actualmente, deben incluirse en este listado a la vía a la costa ,desde Puerto Azul al peaje en Chongón; el entrecruzamiento de vías en la Aurora (Daule)- Samborondón- la T de Salitre; y, en el sur de la ciudad por la Avda. 25 de Julio; y, en el par Venezuela-Portete. 
Otra de las características de este proceso de urbanización es que en la parte norte del área metropolitana, la parroquia urbana La Puntilla del cantón Samborondón, la parroquia rural La Aurora del cantón Daule y la parroquia urbana Pascuales del cantón Guayaquil, se ha consolidado y extendido un número creciente de urbanizaciones y de pequeños programas de viviendas para estratos sociales de ingresos altos y medio altos, que se caracterizan por vender, a más de confort, funcionalidad y lujo, la seguridad ${ }^{15}$. Estas ciudadelas "burbujas" marcan de la manera más explícita la segregación y desigualdad, haciendo que los jóvenes de estos barrios sean extraños en su propia ciudad metropolitana, "yo cruzo el puente y no sé donde estoy", o "ni hablar de un barrio marginal, ni siquiera reconocen los nombres, pero piensan un poco y dicen "El Guasmo", sí, sí he escuchado. Allá vive mi empleada, ella me cuenta"16.

De acuerdo a los informantes calificados- los periódicos de la época, Revista Vistazo, analistas económicos y urbanos- alrededor del 75\% de la inversión municipal, en los primeros años de la administración de Febres Cordero se localizó en el norte y centro de la ciudad y de sus áreas inmediatas, lo que ha hecho que en estos sectores aprovechando los ejes viales rápidos, como de los viaductos y pasos a desnivel construidos a partir de 1992, haya provocado la localización de una serie de nuevos centros comerciales o Malls, producidos por la inversión privada; para después paulatinamente irse repartiendo más "equitativamente" la misma en los posteriores años -al 2000- con la de Nebot aparezcan en el resto del conjunto urbano y particularmente en los sectores populares.

En la actualidad hay 17 grandes y 8 pequeños en funcionamiento y expansión; y, 10 en construcción, en las vías a la Costa, Samborondón y Avda. Benjamín Carrión, como en la vía Perimetral por Isla Trinitaria y Fortín; llegando inclusive hasta el centro histórico de la ciudad (calles Loja y Córdoba) ${ }^{17}$. En este momento, ante el crecimiento del miedo y la inseguridad los habitantes de la ciudad metropolitana visitan a los Malls como antiguamente lo hacían a los

ciudad, pero también genera autoestima y orgullo. Mueve la economía de una ciudad, da trabajo a miles de personas..."; La Revista del Diario El Universo: ídem, 20 de julio del 2003.

15 Un nuevo elemento en la composición del precio de un bien inmobiliario; a partir de una urbanización cerrada, con filtros de seguridad, guardias privados y tecnologías sofisticadas de vigilancia. 
parques, los que se han convertido más en sitios de esparcimiento $\mathrm{y}$, en menor medida, de intercambio comercial.

Un elemento muy particular y que sobresale en el proceso actual de urbanización es el de la (re)conquista del cuadro construido, como lo llama Fernando Carrión ${ }^{18}$, especialmente del casco central e histórico, comercial y financiero, a través de la rehabilitación, o remodelación, de las antiguas edificaciones de cemento de los años 20 hasta de los 70, o de edificios públicos patrimoniales en franco deterioro o deshabitados. En general, en las últimas décadas esta zona ha sido poco atendida debido a que no producía votos para la gestión clientelar, por ello es que no ha habido grandes obras urbanísticas; pero las dos últimas administraciones cantonales han impulsado dos grandes obras de revitalización urbana como son el Proyecto Malecón 2000 y los túneles de los cerros de El Carmen y Santa Ana, éstos últimos permitieron romper una limitación natural para unir el norte con el centro histórico y comercial de la urbe, lo que reforzaría contradictoriamente la centralidad urbana guayaquileña frente a las limitadas experiencias de descentralización/desconcentración existentes al interior de la aglomeración; mientras que el primero es toda una gran operación de renovación urbana del Malecón Simón Bolívar desde las escalinatas Diego Noboa del Cerro Santa Ana, pasando por todo el Malecón hasta el antiguo mercado Sur, como se señala en la publicidad inmobiliaria, que "busca rescatar el potencial turístico, recreacional y comercial del centro histórico de Guayaquil". Como dice Carrión, en el artículo ya mencionado, "superando la óptica del conservacionismo al incorporarle más tiempo "vivido" al pasado".

A lo que hay que agregar, que algunos agentes económicos, especialmente operadores de los sectores bancarios-financieros, han acaparado bastantes edificaciones y lotes baldíos que deben necesariamente revalorizarse con las obras programadas para nuevamente reingresar al mercado. Lo destacable en el caso de Malecón 2000 es la relación entre inversiones públicas y privadas, gestionadas bajo un régimen jurídico de fundación sin el control de la contratación pública pero rindiendo cuenta a la Contraloría General del Estado, produciendo esta obra de renovación urbana y de cambio integral del paisaje a lo largo del estuario del Guayas (aunque hay un mayor nivel de azolvamiento del mismo que es imputable a más de medio siglo de destrucción de las riberas del río Dau- 
le sin medidas de remediación ambiental), a mínimos costos ecológicos según sus promotores y como la más grande operación urbanística en la historia urbana de Guayaquil y de expresión simbólica del poder político y de hegemonía de la sociedad citadina.

También es necesario reseñar que en el centro de la ciudad, como en su periferia, hay áreas del conjunto urbano que necesitan ser recuperadas, a través de programas de rehabilitación para que adquieran vitalidad y se articulen mejor en el tejido urbano metropolitano y a la promoción inmobiliaria; lo que se debía lograr con el aporte del sector público y de las actores sociales y económicos urbanos a través de la donación a la municipalidad del $25 \%$ del impuesto a la renta recabado en el cantón, abolida en la "bronca" Nebot/Correa de esta coyuntura política, una vez más. Para enfrentar lo reseñado se impulsó en esta última década, por parte de las administraciones Febres Cordero/Nebot, un programa municipal de regeneración urbana basado en la inversión por parte de las fundaciones, Malecón 2000 y Guayaquil Siglo XXI, y su recuperación a través de los impuestos municipales revaluados fijados a los corredores viales- prediales beneficiados, como es el caso de la recuperación del patrimonio edilicio existente; especialmente las operaciones realizadas a lo largo de todos los corredores viales 9 de Octubre, Portete, Víctor Emilio Estrada, Malecón de El Salado, calles del casco central, el barrio de El Centenario, el barrio de Las Peñas y el Barrio del Astillero, principalmente y entre otros, como parte del modelo de gestión local empresarial.

Actualmente, se está desarrollando en la Alborada y en las avenidas que conectan el centro con el sur y con el suroeste de la urbe. Esta política urbana es un imperativo en la tarea cotidiana de la administración local por todo lo que implica, y como parte de la conservación y mantenimiento de la nueva identidad urbana, recuperación de la autoestima "impuesta" como leitmotiv de movilización y adhesión; y, como proyecto de hegemonía urbana objetivado en una producción simbólica de la ciudad como expresión de un poder real unificado y manifestación de un dominio partidista-electoral.

De otra parte, es necesario destacar la localización en el norte de la urbe, especialmente en el sector de la vía a la Costa - Chongón, de un conjunto de grandes equipamientos colectivos, construidos o en ejecución, como el nuevo aeropuerto -a entregarse en concesión-; el trasvase del Río Daule a la Península de Santa Elena y la autovía Guayaquil-Salinas (ampliada y completada por el Consejo Provincial y Gobierno Centra-MOP para ser concesionada, pero 
el Presidente Correa se opuso y la gestiona el MTOP), las cuales impulsan, al mismo tiempo, y están induciendo al crecimiento de la ciudad en esa dirección; como también están generando un proceso de acaparamiento y de especulación del suelo en este sector de la aglomeración, el cual ha sido integrado al limite urbano gracia a la Ordenanza de 1991, que está afectando inclusive a las tierras comunales y desalojando a los comuneros de sus terruños ancestrales.

Así mismo, debemos reseñar que todas estas grandes obras, más otras, hacen parte del "Plan de Proyectos Estratégicos de Desarrollo Urbano para Guayaquil" planteados por la Dirección del Plan de Desarrollo Urbano Cantonal, para la primera administración del Alcalde Nebot, 2000-2004, que parece que hasta la fecha está vigente.

En el documento reseñado se menciona que "de qué sirve tener un plan de ordenamiento y control de la ciudad si no se tiene un plan de proyectos estratégicos que promueva la economía y su desarrollo, muchos de estos criterios han sido exigidos y formulados por la Junta Cívica, las Cámaras de la Producción, la Fundación Siglo XXI, Fundación Malecón 2000, CEDEGE (en la actualidad es parte de la Senagua), las Universidades, los medios de comunicación, los transportistas y otros sectores organizados de la ciudad", lo que nunca se ha dado hasta la fecha salvo con las corporaciones y, obviamente, con los empresarios como protagonistas.

En otra parte de este documento, intitulado "Estrategias específicas del desarrollo urbano" se dice lo siguiente: "En el marco de competencia de ciudades y regiones, el concepto básico de la estrategia de desarrollo urbano de la administración del Ab. Jaime Nebot, plantea fundamentalmente potencializar las infraestructuras existentes, modernizar las instalaciones de transporte, promoviendo incentivos y facilitando la inversión para generar desarrollo y mejorar la calidad de vida de la población"196"; la idea fundamental es crear la Singapur de América Latina, para crear un gran mercado en la región" ${ }^{20}$. Aspiración siempre verbalizada, en múltiples eventos realizados, por los grupos hegemónicos guayaquileños pero nunca cristalizada por la diversidad de intereses particulares en los mismos y un escaso tino en la relación con el Estado.

19 Dirección del Plan de Desarrollo Urbano Cantonal DPLANG: Plan de Proyectos Estratégicos de Desarrollo Urbano para Guayaquil; Guayaquil, M.I. Municipalidad de Guayaquil, 2000, 1era Edición.

20 Stratega BDS- Business Development Services (2009); Agenda estratégica de competitividad con responsabilidad social y equidad de la ciudad de Guayaquil y su zona de influencia; Diagnostico de la competitividad territorial de Guayaquil. 
En este contexto de concentración de la inversión pública en el norte y centro, por el desarrollo de los circuitos viales, se ha producido en un lapso de tiempo más o menos corto, esa operación inmobiliaria de gran envergadura -alrededor de \$500 millones de dólares según la prensa especializada- que es Kennedy Norte, que apunta a crear un nuevo espacio para re-localizar al terciario superior de Guayaquil. Desde la perspectiva urbanística e inmobiliaria es una zona de gran futuro, que se ha fuertemente dolarizado, pero también ha sentido los impactos de las crisis de 1999 y de la quiebra del sistema bancariofinanciero como del esquema de dolarización legal (Enero 2000), limitando con ello sus posibilidades de expansión pero incrementando las rentas diferenciadas del suelo urbano en el sector.

Asimismo, en este análisis de la coyuntura de la política urbana guayaquileña no podemos pasar por alto el rol jugado por el Estado, en particular el Municipio, tanto en lo relacionado con el financiamiento público de las operaciones urbanísticas como por la privatización de la gestión municipal y de los equipamientos colectivos impulsados.

Merita destacarse, el cambio que se ha dado en la gestión edilicia en materia de continuidad administrativa como de los planes y programas, ya que mientras entre 1979 y 1992 pasaron por la Municipalidad 7 Alcaldes, desde esta última fecha hasta la actualidad lo han hecho dos. Esto último ha permitido que el Municipio se especialice en la construcción de pasos viales, el mantenimiento del sistema vial y el desarrollo de ciertos equipamientos, como mercados y parques, que si bien han presentado un cambio real en la administración municipal, todavía ésta no es lo suficiente fuerte y creativa para encarar los otros graves problemas que aquejan a la ciudad y sus habitantes, principalmente los vinculados a la pobreza y miseria, la generación de empleos decentes e ingresos dignos, reducción de las inequidades y desigualdades existentes, o ser un promotor activo del desarrollo económico local, entre otros.

Hay que destacar que desde 1994 se ha impulsado un programa masivo de regularización de la tenencia del suelo urbano en las dispersas áreas de "invasión", que se destaca en el accionar municipal como en el incremento significativo de ingresos "propios" por el catastro; pero tampoco éstas se han podido controlar y peor reducir las operaciones ilegales, ni siquiera con la creación del programa habitacional y de lotes con servicios "Mucho Lote" o "Mi Lote", ya que no se entra decididamente a regular estos mercados oligopólicos ni a diversificar la oferta inmobiliaria para la demanda no solvente; lo que también 
es imputable al empobrecimiento masivo agudizado por la dolarización y a la especulación existente. Vale recordar el crecimiento de las invasiones en estas dos décadas hacia el noroeste de la ciudad, inclusive saltando el límite urbano existente y afectando acueductos, tuberías de combustible y al sistema nacional interconectado, que produjo un fuerte enfrentamiento entre Nebot y Correa, como parte de la pugna de poderes.

Para la segunda administración 2005-2009 del alcalde Nebot se planteó una serie de proyectos estratégicos, tanto urbanísticos como de infraestructura y de desarrollo social, ya mencionados que también se están concretando en su tercera administración en la misma lógica y direccionalidad reseñadas.

La visión de la gestión de la ciudad y del ejercicio del poder urbano por parte de las autoridades locales hace que, en estas dos décadas, no se hayan construido verdaderas políticas públicas cuyas continuidades se garanticen con administraciones de signos políticos diferentes debido a la ausencia de participación social y de consultas permanentes al Soberano, el pueblo. Lo que reduce la producción de la ciudad a la "urbe espectáculo", con sospechosos criterios estéticos y bajo nivel de creatividad en un proyecto histórico de aglomeración metropolitana.

\section{Perspectivas del modelo empresarial de gestión local}

Guayaquil ha asumido, una vez más, su tradicional cosmopolitización de puerto internacional (marítimo y aéreo) en la geopolítica del Pacifico Sur y de la cuenca del Pacífico. Para este complejo y desconocido escenario de la Globalización se han desarrollado, y algo planificado, en estas últimas dos décadas un conjunto de obras urbanísticas y modificaciones institucionales que han marcado su desarrollo urbano y el de sus actores sociales y políticos, pero sin definir y consensuar un proyecto histórico de ciudad y de encadenamiento productivo como región incluyente, sostenible y sustentable. Nunca ha habido por parte de las élites guayaquileñas una propuesta y acuerdo de objetivos estratégicos 'para la construcción colectiva de una imagen -objetivo de la ciudad y sus entornos, para el largo plazo.

Esta visión del desarrollo urbano se ha basado en un enfoque tradicional y en una ortodoxia urbanística, como en el ya mencionado regreso y recuperación a la ciudad construida, del centro urbano e histórico, principalmente de sus bienes patrimoniales, paisajes y áreas edificadas deterioradas del casco comercial 
y sus alrededores. No solo es una simple operación de negocio inmobiliario sino que es la creación y desarrollo de un creciente espacio público, léase "colectivo", para uso y disfrute controlado de los usuarios de la ciudad,"controlando a los usuarios de la ciudad bajo estrictas normas de selección y de comportamiento formal impuesto por un discurso moralista por el poder como sucede en la actualidad", según Xavier Andrade, en el texto ya citado. No es la recuperación de espacios para la vida en común, como lo demanda Saskia Sassen ${ }^{21}$, ni para lograr el buen vivir como lo publicita el nacional populismo.

Los sustentos de la Regeneración Urbana y de Malecón 2000, entre otros, como programas de renovación urbana de la municipalidad, que incluyen presupuestos religiosos, conservadores y que alude frecuentemente a la "preservación de la moral y las buenas costumbres" (¿ cuáles y de quiénes?); explicitan también como se construye, real y simbólicamente, la ciudad desde el poder, así como se entretejen las políticas urbanas y la dinámica del poder local, constituyendo un sólido capital político y un modelo de identificación colectiva con "Guayaquil más Ciudad". Es la nueva imagen de la ciudad a vender en el mercado mediático y la urbe del espectáculo.

A lo anterior se agrega, lo que consideramos más trascendente de este proceso de cambio urbano, las modificaciones institucionales que se han producido, entre las que se destacan, la recuperación de la autoestima ciudadana pero como recurso ideológico que rescata no solo los derechos sino también las obligaciones ciudadanas, como la implantación de una cultura tributaria; la institucionalización de una política social con la creación del Departamento de Acción Social y Educación (DASE), marcada por el asistencialismo y una particular visión y práctica de la responsabilidad empresarial; o, el interesante programa de Seguro Social Urbano de salud, entre los más significativos.

Aunque las políticas y programas reseñados no impiden reconocer la existencia de otras actividades que la Alcaldía está impulsando desde su particular cosmovisión de lo qué es una ciudad y la gestión pública local, como la ciudad digital; el del turismo y competitividad, el de manejo del espacio y vía pública con la recientemente declaración pública de peatonización de la calle Panamá hasta el Cerro; el del ordenamiento territorial, o el del nuevo puerto de aguas profundas de Posorja, parroquia rural de Guayaquil. 
No podemos concluir este análisis, sin destacar los temas pendientes en la agenda Municipal, que resaltan las falencias y debilidades del enfoque de gestión empresarial de lo local, para esta administración y las que vendrán en el futuro próximo. Guayaquil como actor de la globalización exige impulsar su competitividad, lo que se traduce en un fortalecimiento y especialización de su base económica con incorporación de valor agregado y generación de un encadenamiento productivo. Agregando, un desarrollo incluyente y equitativo intra e interurbano, la construcción de un gobierno metropolitano que responda a las demandas de la conurbación; más accesibilidad a los servicios urbanos, lucha contra la pobreza, desaparición de la miseria y protección del ambiente urbano que permitan construir una ciudad metropolitana global.

\section{Bibliografía}

ALCALDÍA DE GUAYAQUIL

1995 Esquema urbano de Guayaquil. Guayaquil: Departamento de Planificación Urbana.

2000 Plan de Proyectos Estratégicos de Desarrollo Urbano para Guayaquil. Guayaquil: Dirección del Plan de Desarrollo Urbano Cantonal (DPLANG).

BARRERA, Augusto (coord.)

1999 Ecuador: un modelo para desarmar. Descentralización, disparidades regionales y modo de desarrollo. Quito: Editorial Abya-Yala.

CARVAJAL Fernando (ed.)

1996 Democracia, desarrollo y descentralización. Por una propuesta alternativa. Maestría en Desarrollo Andino Regional e ILDIS. Cuenca.

CASTELLS, Manuel

1997 La era de la información: economía, sociedad y cultura. Madrid: Alianza Editorial.

CONAM-GTZ-CONCOPE-GOBIERNO DE LA PROVINCIA DEL PICHINCHA

s/a Consecuencias de la transferencia de competencias. Quito: Comisión Técnica de descentralización (fotocopias).

CONAM

2000 Propuesta de nuevo modelo de gestión para Ecuador: CONAM-BEDE-GTZ. Quito: Comisión para la descentralización (documento de trabajo).

ESCUELA SUPERIOR POLITÉCNICA DEL LITORAL

2000 Guayas Siglo XXI. Un nuevo Modelo de Desarrollo Regional con Base en el conocimiento. Documento para Análisis interno. Guayaquil (borrador). 
FUENTES, Carlos y Ricardo Lagos

2012 El siglo que despierta. México: Editorial Taurus.

HARDOY, Jorge y Richard Morse (comp.)

1988 Repensando la ciudad de América Latina. Buenos Aires: GEL-IIED.

HERNÁNDEZ, Iván y Martín Velasco (equipo consultor)

2009 Agenda estratégica de competitividad social y equidad de la ciudad de Guayaquil y su zona de influencia. Diagnóstico de la competitividad territorial de Guayaquil. Guayaquil: Stratega BDS-Business Development Services.

MARTÍNEZ, Esperanza (edit.)

2000 El Ecuador Post Petrolero. Quito: Acción Ecológica.

MUÑOZ, Francesc

2008 Urbanalización. Paisajes comunes, lugares globales. Barcelona: Editorial Gustavo Gili.

PGU, PUD, UNCHS, BANCO MUNDIAL, GTZ

1995 Descentralizar en América Latina. Vol. 3. Quito.

RODRÍGUEZ, Carlos (Dir.)

2000 Descentralización desde la diversidad del pensamiento. Quito: Facultad de Ciencias Administrativas de la Universidad Central del Ecuador, Editorial Universitaria.

RUIZ BALLESTEROS, Esteban

2000 Construcción Simbólica de la Ciudad. Política Local y Localismo. Madrid: Miño y Dávila Editores.

SASSEN, Saskia

2007 Una sociología de la globalización. Buenos Aires: Editorial Katz.

Envío 2 de octubre de 2012 - Fecha de aceptación 5 de diciembre de 2012. 